\title{
Prevalence and antimicrobial resistance of Salmonella isolated from lactating cows and in contact humans in dairy farms of Addis Ababa: a cross sectional study
}

\author{
Zelalem Addis $^{1 *}$, Nigatu Kebede ${ }^{2}$, Zufan Sisay ${ }^{2}$, Haile Alemayehu ${ }^{2}$, Alehegne Yirsaw ${ }^{3}$ and Tesfu Kassa ${ }^{2}$
}

\begin{abstract}
Background: Salmonella are the major pathogenic bacteria in humans as well as in animals. Salmonella species are leading causes of acute gastroenteritis in several countries and salmonellosis remains an important public health problem worldwide, particularly in the developing countries. The situation is more aggravated by the ever increasing rate of antimicrobial resistance strains. Cattle have been implicated as a source of human infection with antimicrobial resistant Salmonella through direct contact with livestock and through the isolation of antimicrobial resistant Salmonella from raw milk, cheddar cheese, and hamburger meat traced to dairy farms. Despiite the presence of many studies on the prevalence and antimicrobial susceptibility pattern of Salmonella in Ethiopia, nothing has been said on the degree of the situation among apparently healthy lactating cows and in contact humans. Hence this study was conducted to determine the prevalence and antimicrobial resistance pattern of Salmonella isolates from lactating cows and in contact humans in dairy farms of Addis Ababa.

Methods: a cross sectional study was conducted in Addis Ababa by collecting milk and faecal samples from lactating cows and stool samples from humans working in dairy farms. Samples were pre-enriched in buffered peptone water followed by selective enrichment using selenite cysteine and Rapaport-Vassilidis broths. Isolation and identification was made by inoculating the selectively enriched sample on to Xylose Lysine Deoxycholate agar followed by confirmation of presumptive colonies using different biochemical tests. The Kibry Bauer disk diffusion method was used for antimicrobial sensitivity testing.
\end{abstract}

Results: $10.7 \%$ (21/195) of cows and $13.6 \%$ (3/22) of the human subjects sheded Salmonella. $83 \%$ resistance to two or more antimicrobials and $100 \%$ resistance to ampicillin were observed. Most of the isolates were relatively sensitive to ciprofloxacin, cotrimoxazole, and chloramphenicol.

Conclusion: High proportion of Salmonella isolates developed resistance to the commonly prescribed antimicrobials and this may be a considerable risk in the treatment of clinical cases. So, wise use of antimicrobials must be practiced to combat the ever increasing situation of antimicrobial resistance.

\section{Background}

Salmonella are the major pathogenic bacteria in humans as well as in animals. Salmonella species are leading causes of acute gastroenteritis in several countries and salmonellosis remains an important public health

\footnotetext{
*Correspondence: zelalemaddis@ymail.com

'University of Gondar, College of Medicine and Health Science, Department of Medical Laboratory Science, P.O.Box 196, Gondar, Ethiopia

Full list of author information is available at the end of the article
}

problem worldwide, particularly in the developing countries [1]. Salmonellosis is the most common food borne disease in both developing and developed countries, although incidence rates vary according to the country [2]. The fecal wastes from infected animals and humans are important sources of bacterial contamination of the environment and the food chain [3].

Antimicrobial-resistant Salmonella are increasing due to the use of antimicrobial agents in food animals at

\section{C) Biomed Central}


sub-therapeutic level or prophylactic doses which may promote on-farm selection of antimicrobial resistant strains and markedly increase the human health risks associated with consumption of contaminated meat products [4-6]. Cattle have been implicated as a source of human infection with antimicrobial resistant Salmonella through direct contact with livestock and through the isolation of antimicrobial resistant Salmonella from raw milk, cheddar cheese, and hamburger meat traced to dairy farms. Antimicrobial use in animal production systems has long been suspected to be a cause of the emergence and dissemination of antimicrobial resistant Salmonella [7].

Different studies conducted in Ethiopia indicated considerable prevalence of Salmonella both in veterinary and public set ups $[4,5,8,9]$ but reports from apparently healthy lactating cows and humans attending these cows is very limited. So the aim of this study was to determine the prevalence and antimicrobial susceptibility pattern of Salmonella isolates from apparently healthy lactating cows and in contact humans in dairy farms of Addis Ababa.

\section{Methods}

\section{Sample Size Determination and Sample Collection Technique}

The study was conducted from February, 2010 up to May, 2010 in Addis Ababa which has a bovine population of 58,568 [10].

Sample size was determined using prevalence rate of $7.1 \%$ from previous studies [8] at 5\% level of significance and the following formula was employed [11]

$$
\mathrm{N}=\frac{\left(\mathrm{Z}_{\alpha / 2}\right)^{2} \times \mathrm{P}(1-\mathrm{P})}{\mathrm{d}^{2}}
$$

Based on the above formula the calculated sample size was 201.

A total of 195 lactating cows and 22 humans from 23 farms were randomly selected and included in this study. A total of 390 samples from cows (195 faecal and 195 milk) and 22 stool samples from humans were collected for the detection of Salmonella. The faecal specimens of cows were collected in a clean sterile air tight stool cup directly from the rectum. Approximately $20 \mathrm{ml}$ of milk was collected in a sterile universal bottle after the cows were restrained in self-locking stanchions. 30 gms of stool samples, those do not have direct contact with the environment were collected in sterile stool cup with an applicator stick from volunteer individuals working in the dairy farms. The samples were transported using an ice box and analyzed at Aklilu Lemma Institute of Pathobiology, Addis Ababa University.

\section{Isolation and Identification of Salmonella}

The isolation and identification of Salmonella was performed at the medical microbiology laboratory of Aklilu Lemma Institute of Pathobiology using techniques recommended by International Organizations for Standardization (ISO-6579, 2000), and those recommended by the Global Salmonella Surveillance (GSS) and National Health Services for Wales (NHS) [12-14]. The isolation and identification involves three steps; $1 \mathrm{gm}$ of faecal sample or $1 \mathrm{ml}$ of milk was pre-enriched with 9 $\mathrm{ml}$ of buffered peptone water (BPW) (Oxoid CM509, Basingstoke, England) and incubated for $24 \mathrm{hrs}$ at $37^{\circ} \mathrm{C}$. A portion $(0.1 \mathrm{ml})$ of the pre-enriched cultured was transferred to $10 \mathrm{ml}$ of selenite cysteine (SC) (Himedia M025, Mumbi) broth and another $0.1 \mathrm{ml}$ portion was transferred to10 $\mathrm{ml}$ of Rappaport and Vassilidis (RV) broth (Merk, Darmstadt, Germany) broth and incubated at $37^{\circ} \mathrm{C}$ and $42^{\circ} \mathrm{C}$ for $24 \mathrm{hrs}$ respectively. Finally, from the selective enrichment media the sample was inoculated on to Xylose Lysine Deoxycholate (XLD) (Oxoid CM0469, Basingstoke, England) agar and incubated at $37^{\circ} \mathrm{C}$ for $24 \mathrm{hrs}$ and the incubation was prolonged to 48 hrs for those that did not show any growth during the 24 hrs incubation. Characteristic Salmonella colonies, having a slightly transparent zone of reddish color and a black center, were sub-cultured on nutrient agar (Oxoid CM0003, Basingstoke, England) and confirmed biochemically using triple sugar iron agar (TSI) (Oxoid CM0277, Basingstoke, England), Christensen's urea agar (Oxoid CM53, Basingstoke, England), lysine iron agar (LIA) (Oxoid CM381, Basingstoke, England), Voges Proskauer (VP), methyl red (MR) (Micromaster Thane, India), and Indole tests (Becton Dickinson, USA) [12].

\section{Antimicrobial susceptibility test of isolates}

The antimicrobial susceptibility test of the isolates were performed according to the National Committee for Clinical Laboratory Standards (NCCLS) method using Kibry-Bauer disk diffusion test on Mulle-Hinton agar (Oxoid CM0337 Basingstoke, England) [15]. Eshercia coli ATCC 25922 was used as a quality control organism for the antimicrobial susceptibility test (Hendriksen, 2002). The isolates were tested for the following antibiotics; ampicillin $(10 \mu \mathrm{g})$, nitrofurantoine $(300 \mu \mathrm{g})$, streptomycin $(10 \mu \mathrm{g})$, kanamycin $(30 \mu \mathrm{g})$, gentamycin $(10 \mu \mathrm{g})$, ceftriaxone $(30 \mu \mathrm{g})$, chloramphenicol $(30 \mu \mathrm{g})$, tetracycline $(30 \mu \mathrm{g})$, ciprofloxacin $(5 \mu \mathrm{g})$ all from Oxoid, England and cotrimoxazole (Thrimethoprim sulfmethoxazole) (25 $\mathrm{gg}$ ) (Micromaster, India).

\section{Data Analysis}

Data was analyzed using SPSS version 13 computer software (SPSS 13.0 Command Syntax Reference. SPSS Inc., Chicago, 2004) and presented in tables and graphs. The 
Chi-square test was utilized to assess significant differences in antimicrobial resistance of Salmonella isolates from human and cow and from isolates of milk and faeces of cows. A difference was taken as significant at a p-value less than 0.05 .

Ethical consideration: the study was ethically approved by the Institutional Review Board of Aklilu Lemma Institute of Pathobiology, Addis Ababa University. More over both informed and written consent were obtained from the human subjects.

\section{Result}

From 23 farms included in this study detection of Salmonella was successful in $11(47.8 \%)$ dairy farms. The relative prevalence within different farms was $57.1 \%$ (4/ 6), $33.33 \%(2 / 6)$ and $83.33 \%$ (5/6) for small, medium and large scale farms, respectively.

From the total of 195 dairy cows tested, 10.76\% (21/ 195) were positive for Salmonella, either from milk or faeces. Of these cows, $71.4 \%(15 / 21)$ were positive from faecal sample and $28.6 \%(6 / 21)$ were positive from milk sample. None of the cows were positive both from the faeces and milk sample, and no significant difference was found in the isolation of Salmonella from faecal sample and milk samples $\left(\mathrm{x}^{2}=0.516, \mathrm{P}\right.$-value $\left.=0.473\right)$. The stool samples were collected from the 22 volunteer individuals working in the dairy farms and the result showed that only $13.63 \%(3 / 22)$ of them became positive for Salmonella (Table 1).

All the twenty four isolates of Salmonella, from cows and humans, were subjected to a panel of ten antimicrobials. The antimicrobial susceptibility pattern of the isolates indicated that all isolates were $100 \%, 66.7 \%$, and $58.3 \%$ resistant to ampicillin, streptomycin and nitrofurantoine respectively. On the other hand the isolates were, $91.7 \%, 87.5 \%$ and $75 \%$ sensitive to ciproflocacillin and cotrimoxazole, chloramphenicol and ceftriaxone respectively (Figure 1 ).

83.3\% of both human and cow isolates showed resistance for two or more of the antimicrobials tesed. Form these resistance isolates, most of them (20\%) showed resistance to ampicillin and streptomycin followed by resistance to gentamycin, ampicillin, streptomycin, kanamycin and nitrofurantoine (15\%) and to ampicillin, streptomycin and nitrofurantoine (10\%). One milk isolate and one faecal isolate of cow showed multiple antimicrobial resistances to $60 \%$ of the antimicrobials tested (Table 2).

Salmonella isolated from milk sample showed 100\% resistance to ampicillin and streptomycin while they were $83.3 \%$ sensitive to ciprofloxacin, cotrimoxazole and ceftriaxone. Faecal isolates of cows showed $100 \%$ sensitivity to ciprofloxacin followed by cotrimoxazole and chloramphenicol (93.3\%). 66.66\% resistance to streptomycin was observed among faecal isolates of cows. All the human isolates showed resistance only for ampicillin and they were sensitive to most antimicrobials tested with 100\% intermediate resistance to streptomycin. Significance difference in the antimicrobial resistance of isolates from different samples was not observed (Table 3).

\section{Discussion}

In this study the prevalence of Salmonella in apparently healthy lactating dairy cows is larger (10.76\%) as compared to other studies, even though most of the reports are on slaughtered cattle from abattoirs and ready to eat food items $[6,8,9]$. Hence lactating cows could be potential sources of Salmonella infection for individuals working in dairy farms and for the community at large.

Alemayehu et al., 2003 (8) reported a prevalence of $7.1 \%$ from apparently healthy slaughtered cattle which is less than the present report. This difference may be

Table 1 Salmonella Isolates from lactating dairy cows and individuals working in the dairy farms

\begin{tabular}{|c|c|c|c|c|c|c|}
\hline \multirow[t]{2}{*}{ Sample type } & \multicolumn{2}{|c|}{ Address of farms } & \multicolumn{3}{|l|}{ Farm size } & \multirow[t]{2}{*}{$X^{2}(P-$ value $)$} \\
\hline & Bole & Yeka & Small & Medium & Large & \\
\hline \multicolumn{7}{|l|}{ Faeces of cows } \\
\hline Positive & $5(5.9 \%)$ & $10(9.1 \%)$ & $2(3.9 \%)$ & $5(11.6 \%)$ & $8(7.9 \%)$ & $1.967(0.374)$ \\
\hline Negative & $80(94.1 \%)$ & $100(90.9 \%)$ & $49(96.1 \%)$ & $38(88.4 \%)$ & $93(92.1 \%)$ & \\
\hline Total & $85(100 \%)$ & $110(100 \%)$ & $51(100 \%)$ & $43(100 \%)$ & $101(100 \%)$ & \\
\hline \multicolumn{7}{|l|}{ Milk of cows } \\
\hline Positive & $5(5.9 \%)$ & $1(1 \%)$ & $5(9.8 \%)$ & $1(2.3 \%)$ & $\mathrm{O}(0 \%)$ & $11.02(0.004)$ \\
\hline Negative & $80(94.1 \%)$ & 109(99\%) & $46(90.2 \%)$ & $42(97.7 \%)$ & $101(100 \%)$ & \\
\hline Total & $85(100 \%)$ & $110(100 \%)$ & $51(100 \%)$ & $43(100 \%)$ & $101(100 \%)$ & \\
\hline \multicolumn{7}{|l|}{ Human stool } \\
\hline Positive & $2(20 \%)$ & $1(8.3 \%)$ & $0(0 \%)$ & $1(25 \%)$ & $2(15.4 \%)$ & $1.262(0.532)$ \\
\hline Negative & $8(80 \%)$ & $11(91.7 \%)$ & $5(100 \%)$ & $3(25 \%)$ & $11(84.6 \%)$ & \\
\hline Total & 10(100\%) & $12(100 \%)$ & $5(100 \%)$ & $4(100 \%)$ & $13(100 \%)$ & \\
\hline
\end{tabular}

Numbers in parenthesis are percentages. 


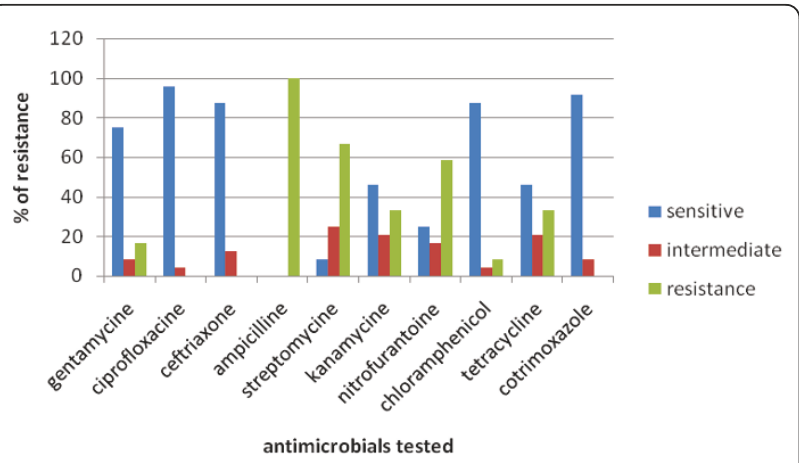

Figure 1 Percentage activity of antimicrobials tested against Salmonella isolates from lactating dairy cows and individuals working in the dairy farms.

attributed to the difference in the tests used, since preenrichment steps using buffered peptone water was employed in this study. On the other hand reports from England $(0.2 \%$ and $4 \%)$ and from Northern Thailand (3\%) are much lower than the current investigation [16-18]. But a report from Cameroon by Akoachere et al., 2009 [19] indicated a very high prevalence (27\%) of Salmonella among cattle. This may be due to the difference in the living condition, like housing conditions, feeding habits, types of feed given for the cattle, of the two cattle populations. A comparable result, 9.96\%, was reported from four states of USA [20].

The prevalence of Salmonella among individuals working in dairy farms of Addis Ababa was 13.63\%. The result is higher than a study conducted by Alemayehu et al., 2003 [8] and Zewdu and Cornelius, 2009 [6] who reported a prevalence of $6 \%$ and $7.6 \%$, respectively. The difference may be due to different working environment, hence different hygienic status, of study subjects. This higher prevalence is a concern to the dairy farms that provide milk and milk products to the community since cross contamination from infected individuals could be a potential source of food borne infections.

Resistance for two or more of antimicrobials (83.3\%) which was observed in this study was higher than other studies conducted in Ethiopia [5,6,8,21] and elsewhere in the world $[1,2,22,23]$. This difference may be due to the increasing rate of inappropriate utilization of antibiotics in the dairy farms which favors selection pressure that increased the advantage of maintaining resistance genes in bacteria [24,25].

Zewdu and Cornelius (2009) [6] reported that the isolates of Salmonella from food items and personnel from Addis Ababa were resistant to the commonly used antibiotics including streptomycin, ampicillin, and tetracycline. The result of the current research also indicated resistance of Salmonella isolates to commonly used antimicrobials including ampicillin, streptomycin, nitrofurantoine, kanamycine and tetracycline, with resistance rate of $100 \%, 66.7 \%, 58.3 \%$ and $33.3 \%$, respectively.

All the isolated Salmonella, in the current study, were $100 \%$ resistant to ampiciliin. This finding is in line with previous reports from South India [26], from Nigeria [27] and from Cameroon [19] which reported a similar $100 \%$, over $90 \%$ and $100 \%$ resistance to ampicillin, respectively. Hghi et al. (2009) [28] reported a resistance rate of $60.3 \%$ and $72.7 \%$ in different study periods among human isolates from Iran, which is slightly lower than the current finding.

Ciprofloxacin showed a good antimicrobial activity against both human and cow isolates. This is also comparable with the result reported by Akinyemia et al., 2005 [27] from Nigeria, among human isolates and with that reported by Molla et al., 2006 [5] from central part of Ethiopia among isolates of sheep and goat. Though no data has indicated this, the effectiveness of such drugs like ciprofloxacin may be because they are not widely used in countries like Ethiopia and other African countries.

Table 2 Multiple antimicrobial resistance profile of Salmonella isolates from lactating dairy cows and humans working in dairy farms

\begin{tabular}{lll}
\hline Number of antimicrobial resistance & Antimicrobial resistance pattern (number of isolates) & Number of isolates (\%) \\
\hline Two & AMP, S (4) & $6(25)$ \\
Three & AMP, TE (2) & $4(16.7)$ \\
& AMP, S, F (2) & \\
Four & AMP, S, TE (1) & $4(16.7)$ \\
& AMP, K, F (1) & \\
& AMP, S, K, F (1) \\
Five & CN, AMP, S, F (1) & $4(16.7)$ \\
Six & AMP, S, F, TE (1) & \\
\hline
\end{tabular}

Key to Abbreviations: AMP (ampicillin), S (streptomycin), K (kamanycine), F (nitrofurantoine), CN (gentamycin), TE (tetracycline), C (chloramphenicol). 
Table 3 Antimicrobial susceptibility pattern of Salmonella isolates from lactating dairy cows and humans working in dairy farms

\begin{tabular}{|c|c|c|c|c|}
\hline \multirow[t]{2}{*}{ Antimicrobials tested } & \multicolumn{3}{|c|}{ Type of sample } & \multirow[t]{2}{*}{$X^{2}$ (P-value) } \\
\hline & Milk of cows & Faeces of cows & Human stool & \\
\hline \multicolumn{5}{|l|}{ Gentamycin } \\
\hline Sensitive & $4(66.7)$ & $11(73.3)$ & $3(100)$ & $2.535(0.792)$ \\
\hline Intermediate & $0(0)$ & $2(13.3)$ & $0(0)$ & \\
\hline Resistance & $2(33.3)$ & $2(13.3)$ & $0(0)$ & \\
\hline \multicolumn{5}{|l|}{ Ciprofloxacin } \\
\hline Sensitive & $5(83.3)$ & $15(100)$ & $3(100)$ & $3.118(0.708)$ \\
\hline Intermediate & $1(16.7)$ & $0(0)$ & $0(0)$ & \\
\hline Resistance & $0(0)$ & $0(0)$ & $0(0)$ & \\
\hline \multicolumn{5}{|l|}{ Ceftriaxone } \\
\hline Sensitive & $5(83.3)$ & 13(86.7) & $3(100)$ & $0.664(1)$ \\
\hline Intermediate & $1(16.7)$ & $2(13.3)$ & $0(0)$ & \\
\hline Resistance & $0(0)$ & $0(0)$ & $0(0)$ & \\
\hline \multicolumn{5}{|l|}{ Ampicilline } \\
\hline Sensitive & $0(0)$ & $0(0)$ & $0(0)$ & \\
\hline Intermediate & $0(0)$ & $0(0)$ & $0(0)$ & \\
\hline Resistance & $6(100)$ & $15(100)$ & $3(100)$ & \\
\hline \multicolumn{5}{|l|}{ Streptomycin } \\
\hline Sensitive & $0(0)$ & $2(13.3)$ & $0(0)$ & $9.422(0.083)$ \\
\hline Intermediate & $0(0)$ & $3(20)$ & $3(100)$ & \\
\hline Resistance & $6(100)$ & $10(66.7)$ & $0(0)$ & \\
\hline \multicolumn{5}{|l|}{ Kanamycine } \\
\hline Sensitive & $2(33.3)$ & $7(46.7)$ & $2(66.7)$ & $4.834(0.167)$ \\
\hline Intermediate & $0(0)$ & $4(26.7)$ & $1(33.3)$ & \\
\hline Resistance & $4(66.7)$ & $4(26.7)$ & $0(0)$ & \\
\hline \multicolumn{5}{|l|}{ Nitrofurantoine } \\
\hline Sensitive & $2(33.3)$ & $3(20)$ & $2(66.7)$ & $8.303(0.083)$ \\
\hline Intermediate & $0(0)$ & $3(20)$ & $1(33.3)$ & \\
\hline Resistance & $4(66.7)$ & $9(40)$ & $0(0)$ & \\
\hline \multicolumn{5}{|l|}{ Tetracycline } \\
\hline Sensitive & $2(33.3)$ & $8(53.3)$ & $1(33.3)$ & $2.061(0.875)$ \\
\hline Intermediate & $1(16.7)$ & $3(20)$ & $1(33.3)$ & \\
\hline Resistance & $3(50)$ & $4(26.7)$ & $1(33.3)$ & \\
\hline \multicolumn{5}{|l|}{ Chloramphenicol } \\
\hline Sensitive & $4(66.7)$ & 14(93.3) & $3(100)$ & 4.605(0.333) \\
\hline Intermediate & $1(16.7)$ & $0(0)$ & $0(0)$ & \\
\hline Resistance & $1(16.7)$ & $1(6.7)$ & $0(0)$ & \\
\hline \multicolumn{5}{|l|}{ Cotrimoxazole } \\
\hline Sensitive & $5(83.3)$ & 14(93.3) & $3(100)$ & $1.289(0.792)$ \\
\hline Intermediate & $1(16.7)$ & $1(6.7)$ & $0(0)$ & \\
\hline Resistance & $0(0)$ & $0(0)$ & $0(0)$ & \\
\hline
\end{tabular}

Numbers in parenthesis are percentages.

In the current study cotrimoxazole (trimethoprim-sulfametoxazole) showed a good antimicrobial activity against all isolates and no resistant isolate against this drug was detected. This result is lower than the reports by Rotimi et al., 2008 [1] from Kuwait and United Arab Emirates who reported a resistance rate of $26.1 \%$ and $8.9 \%$, respectively. Even though cotrimoxazole has been widely available the reason of its effectiveness until this times need investigations.

\section{Conclusion}

Investigating the prevalence and antimicrobial resistance of Salmonella from cattle and incontact human in dairy farms is of paramount importance to design methods of 
minimizing the possible transmission of Salmonella between humans and cattle. Moreover it important in combating the emergence of antibiotic resistant strains of Salmonella. The information gathered in this cross sectional study, together with other similar studies, is important to achieve the aforementioned importance of studying Salmonella in dairy farms.

In general from this cross sectional study it can be concluded that the prevalence of Salmonella in lactating cows and individuals working in dairy farms in Addis Ababa is $10.76 \%$ and $13.63 \%$ respectively. This result is significantly high to be a potential source of food borne salmonellosis. High proportion (83.3\%) of Salmonella isolates were resistant to two or more of the antimicrobials that are commonly used in the veterinary and public health set up. This may pose difficulties in the treatment of human clinical cases and other bacterial diseases.

The currents study indicated the necessity of a further investigation on the prevalence and antimicrobial susceptibility pattern of Salmonella, by considering it as a potential food borne pathogen, starting from the farm to table. Molecular characterization of the isolates with emphasis on resistant strains is also necessary to identify mechanisms of antibiotic resistance. More over judicious and prudent use of antimicrobials in the veterinary and public health sectors is mandatory since high rate of antimicrobial resistant Salmonella isolates were identified.

\section{Acknowledgements \\ The authors thank Aklilu Lemma Institute of Pathobiology, Addis Ababa University, for granting this research, Addis Ababa city administration agricultural office, especially Shola Animal Health Laboratory, for their collaboration during sample collection and Ms. Abebech Engdaw for her support during laboratory work. We would like to thank dairy farm owners and other individuals working in dairy farms for their participation in this study.}

\section{Author details \\ ${ }^{1}$ University of Gondar, College of Medicine and Health Science, Department of Medical Laboratory Science, P.O.Box 196, Gondar, Ethiopia. ${ }^{2}$ Addis Ababa University, Aklilu Lemma Institute of Pathobiology, P.O.Box 1176, Addis Ababa, Ethiopia. ${ }^{3}$ National Animal Health Diagnostic and Investigation Center Research Center (NAHDIC), P.O.Box 04, Sebeta, Ethiopia.}

\section{Authors' contributions}

ZAM conceived the study, undertook statistical analysis and drafted the manuscript. NKW, ZSW, HAG, AWY and TK initiated the study and made major contributions to the study design and statistical analysis. All authors contributed to the writing of the manuscript and approved the submitted version of the manuscript.

\section{Competing interests}

The authors declare that they have no competing interests.

Received: 25 February 2011 Accepted: 19 August 2011 Published: 19 August 2011

\section{References}

1. Rotimi VO, Jamal W, Pal T, Sonnevend A, Dimitrov TS, Albert MJ: Emergence of multidrug-resistant Salmonella spp. and isolates with reduced susceptibility to ciprofloxacin in Kuwait and the United Arab Emirates. Diagn Microbiol Infect Dis 2008, 60:71-7.

2. Stevens A, Kabore $Y$, Perrier-Gros-Claude JD, Millemann $Y$, Brisabois A, Catteau M, Cavin J, Dufour B: Prevalence and antibiotic-resistance of Salmonella isolated from beef sampled from the slaughterhouse and from retailers in Dakar (Senegal). Int J Food Microbiol 2006, 110:178-86.

3. Ponce E, Khan AA, Cheng CM, Summage WC, Cerniglia CE: Prevalence and characterization of Salmonella enteric serovar Weltevreden from imported seafood. Food Microbiology 2008, 25:29-35.

4. Molla B, Mesfin A, Alemayehu D: Multiple antimicrobial resistant Salmonella serotypes isolated from chicken carcases and giblets in Debre Zeit and Addis Ababa, Ethiopia. Ethiop J Health Dev 2003, 17:131-149.

5. Molla W, Molla B, Alemayehu D, Muckle A, Cole L, Wilkie E: Occurrence and antimicrobial resistance of Salmonella serovars in apparently healthy slaughtered sheep and goats of central Ethiopia. Trop Anim Health Prod 2006, 38:455-62.

6. Zewdu E, Cornelius P: Antimicrobial resistance pattern of Salmonella serotypes isolated from food items and personnel in Addis Ababa, Ethiopia. Trop Anim Health Pro 2009, 41:241-9.

7. Alexander KA, Warnick LD, Wiedmann M: Antimicrobial resistant Salmonella in dairy cattle in the United States. Vet Res Com 2009, 33:191-209.

8. Alemayehu D, Molla B, Muckle A: Prevalence and antimicrobial resistance pattern of Salmonella isolates from apparently healthy slaughtered cattle in Ethiopia. Trop Anim Health Prod 2003, 35:309-19.

9. Ejeta G, Molla B, Alemayehu D, Muckle A: Salmonella serotypes isolated from minced meat beef, mutton and pork in Addis Ababa, Ethiopia. Revue Med Vet 2004, 155:547-551.

10. Addis Ababa City Council. [http://www.ethioembassy.org.uk/about_us/ regional_states/addis_ababa_city_council.htm].

11. Thrusfield M: Veterinary Epidemiology. London: Blackwell Science; 1995

12. Hendriksen RS: A global Salmonella surveillance and laboratory support project of the World Health Organization: Laboratory Protocols (Isolation of Salmonella)., 42003.

13. Hendriksen RS: Aglobal Salmonella surveillance and laboratory support of the World Health Organization: Laboratory Protocols (Identification of Salmonella)., 42003.

14. Health Protection Agency: Detection of Salmonella species. National Standard method F 13 issue 3.1. 2008 [http://www.hpa-standardmethods. org.uk/pdf_sops.asp].

15. Hendriksen RS: A global Salmonella surveillance and laboratory support project of the World Health Organization: Laboratory Protocols (Susceptibility testing of Salmonella using disk diffusion)., 32002.

16. Davies RH, Dalziel R, Gibbens JC, Wilesmith JW, Ryan JM, Evans SJ, Byrne C, Paiba GA, Pascoe SJS, Teale CJ: National survey for Salmonella in pigs, cattle and sheep at slaughter in Great Britain (1999-2000). J Appl Microbiol 2004, 96:750-60.

17. Bywater $\mathrm{R}$, Deluyker $\mathrm{H}$, Deroover $\mathrm{E}$, de Jong $\mathrm{A}$, Marion $\mathrm{H}$, McConville $\mathrm{M}$, Rowan T, Shryock T, Shuster D, Thomas V, Valle M, Walters J: A European survey of antimicrobial susceptibility among zoonotic and commensal bacteria isolated from food-producing animals. J Antimicrob Chemother 2004, 54:744-54.

18. Padungtod $\mathrm{P}$, Kaneene JB: Salmonella in food animals and humans in northern Thailand. Int J Food Microbiol 2006, 108:346-54

19. Akoachere TKJ, Tanih FN, Ndip ML, Ndip NR: Phenotypic Characterization of Salmonella Typhimurium Isolates from Food-animals and Abattoir Drains in Buea, Cameroon. J Health Popul Nutr 2009, 27:1-7.

20. Callaway TR, Keen JE, Edrington TS, Baumgard LH, Spicer L, Fonda ES, Griswold KE, Overton TR, VanAmburgh ME, Anderson RC, Genovese KJ, Poole TL, Harvey RB, Nisbet DJ: Fecal prevalence and diversity of Salmonella species in lactating dairy cattle in four states. J Dairy Sci 2005, 88:3603-8.

21. Sibhat B, Molla Zewde B, Zerihun A, Muckle A, Cole L, Boerlin P, Wilkie E, Perets A, Mistry K, Gebreyes WA: Salmonella Serovars and Antimicrobial Resistance Profiles in Beef Cattle, Slaughterhouse Personnel and Slaughterhouse Environment in Ethiopia. Zoonoses Public Health 2009. 
22. Al-Bahry SN, Elshafie AE, Al-Busaidy S, Al-Hinai J, Al-Shidi I: Antibioticresistant Salmonella spp. from human and non-human sources in Oman. East Mediterr Health J 2007, 3:49-55.

23. Khaitsa ML, Kegode RB, Doetkott DK: Occurrence of antimicrobial-resistant Salmonella species in raw and ready to eat turkey meat products from retail outlets in the midwestern United States. Foodborne Pathog Dis 2007, 4:517-25.

24. Mathew AG, Cissell $R$, Liamthong $S$ : Antibiotic Resistance in Bacteria Associated with Food Animals: A United States Perspective of Livestock Production. Foodborne Path Dis 2007, 4:115-133.

25. McGeer AJ: Agricultural antibiotics and resistance in human pathogens: Villain or scapegoat? CMAJ 1998, 159:1190-1120.

26. Suresh T, Hatha AA, Sreenivasan D, Sangeetha N, Lashmanaperumalsamy P: Prevalence and antimicrobial resistance of Salmonella enteritidis and other Salmonellas in the eggs and egg-storing trays from retail markets of Coimbatore, South India. Food Microbiol 2006, 23:294-9.

27. Akinyemia KO, Smithb SI, Oyefolua BAO, Cokerc AO: Multidrug resistance in Salmonella enteric serovar typhi isolated from patients with typhoid fever complications in Lagos, Nigeria. Public Health 2005, 119:321-327.

28. Hghi TM, Monajemzadeh M, Kashi L: Trends in antimicrobial resistance of faecal Shigella and Salmonella isolates in Tehran, Iran. Indian J Patho Microbiol 2009, 52:52-55.

\section{Pre-publication history}

The pre-publication history for this paper can be accessed here: http://www.biomedcentral.com/1471-2334/11/222/prepub

\section{doi:10.1186/1471-2334-11-222}

Cite this article as: Addis et al:: Prevalence and antimicrobial resistance of Salmonella isolated from lactating cows and in contact humans in dairy farms of Addis Ababa: a cross sectional study. BMC Infectious Diseases 2011 11:222.

\section{Submit your next manuscript to BioMed Central and take full advantage of:}

- Convenient online submission

- Thorough peer review

- No space constraints or color figure charges

- Immediate publication on acceptance

- Inclusion in PubMed, CAS, Scopus and Google Scholar

- Research which is freely available for redistribution

Submit your manuscript at www.biomedcentral.com/submit 